УДК 574.474: 598.11+597.8

DOI $10.21661 / \mathrm{r}-115117$

\title{
О.П. Вознийчук
}

\section{ОЦЕНКА ХАРАКТЕРА ВЛИЯНИЯ ТУРИСТИЧЕСКОГО ПРИРОДОПОЛЬЗОВАНИЯ НА НАСЕЛЕНИЕ ЗЕМНОВОДНЫХ И ПРЕСМЫКАЮЩИХСЯ КАТУНСКОГО РЕКРЕАЦИОННОГО РАЙОНА РЕСПУБЛИКИ АЛТАЙ}

Аннотация: на основе количественных данных, собранных мармрутным методом в различных ландиафтах Катунского рекреационного района Республики Алтай, в данной статье показано, что туристско-рекреационное природопользование оказывает неоднозначное воздействие на население земноводных и пресмыкаюшихся. Установлено, что характер изменений в сообщцествах зависит от интенсивности природопользования, а также степени увлажненности местообитаний. В условиях умеренной и низкой увлажнённости высокий уровень рекреации в цуелом оказывает негативное воздействие, а в более влажнblх биотопах наоборот способствует увеличению видового богатства, суммарного обилия и разнообразия.

Ключевые слова: земноводные, пресмыкающиеся, рекреация, население, антропогенная нагрузка.

\section{O.P. Vozniychuk}

\section{ASSESSMENT OF THE CHARACTER OF TOURISTIC ACTIVITY IMPACT ON THE POPULATION OF AMPHIBIANS AND REPTILES OF THE KHATUN RECREATIONAL AREA IN THE REPUBLIC OF ALTAI}

Abstract: on the basis of quantitative data, collected by means of routing method in a number of landscapes of the Katun recreational area in the Republic of Altai, it is shown in this article that the touristic activity impacts ambiguously on the reptiles and amphibians' population. The character of the changes in the population depends on the intensity of the touristic activity, and on the humidity degree of this or that area. Within areas with moderate and low humidity high degree of recreation 
impacts basically negatively; in more humid areas on the contrary it promotes growth species richness, total abundance and diversity.

Keywords: amphibians, reptiles, recreation, population, anthropogenic load.

Алтай, находясь на стыке природных зон, религий и культур вот уже более 100 лет притягивает к себе исследователей и туристов со всего мира. Ценность рекреационных ресурсов Республики Алтай определяется в первую очередь ландшафтными и климатическими условиями данной территории для массового отдыха, научно-познавательного, спортивного, экологического и других видов туризма $[11$, c. 416]. Усиливающийся с каждым годом поток организованных и неорганизованных туристов (около 1,5 млн человек), строительство объектов туриндустрии оказывает негативное влияние на состояние природных комплексов и систем, ускоряя процесс их деградации [6].

Наиболее сложная экологическая обстановка, в том числе из-за проблем размещения и утилизации образующихся в больших объёмах твердых и жидких бытовых отходов, вытаптывания, захламления, вырубок кустарников и деревьев [1, с. 68], складывается в отдельных участках водоохранных зон рек, в том числе и реки Катунь [1, с. 13-14].

Несмотря на то, что проблеме влияния рекреационного природопользования в Республике Алтай последнее время уделяется большое внимание [7, с. $341 ; 10$, с. 382-384], всё же освещена она односторонне, не указывая на характер этого воздействия на биоту. Это связано, в большей степени, с недостатком сведений об изменениях в сообществах различных групп животных в связи с трансформацией среды их обитания, происходящих под воздействием антропогенных факторов. Поэтому Катунский участок выбран для исследований не случайно. Связывая основные автомобильные магистрали и являясь своеобразными «воротами» в Республику Алтай, это один из самых загруженных в транспортном и туристическом отношении участок. В 2016 году подобные исследования о влиянии рекреационного природопользования на сообщества дневных бабочек проведены в этом районе П.Ю. Малковым [5, с. 255]. 
Для локальных оперативных исследований предпочтительней использовать виды животных, которые обладают активным обменом веществ, что способствует быстрому проявлению воздействия негативных внешних факторов на организм, вести оседлый образ жизни, встречаться повсеместно на изучаемой территории, должны быть хорошо изучены [8, с. 20]. Всем этим требованиям отвечают земноводные и пресмыкающиеся и могут быть использованы в качестве объектов для выявления степени дивиации ландшафтов.

Цель представленной работы - оценить характер влияния туристскорекреационного природопользования на сообщества амфибий и рептилий на примере Катунского рекреационного района.

\section{Район работ, материалы и методы}

Исследования по выявлению степени воздействия на состояние населения земноводных и пресмыкающихся проводили в четырех низкогорных ландшафтах Катунского рекреационного района Алтая, выделенного по комплексу природно-экономических характеристик [20, с. 667]. Население амфибий и рептилий в каждом из ландшафтов оценивали в двух вариантах - с высоким и относительно низким уровнем антропогенного воздействия.

Низкогорные сосново-березовые леса долины реки Катунь располагаются вдоль живописных участков и представляют собой места массового неорганизованного и частично организованного отдыха туристов на Алтае. Более удалённые участки аналогичных лесных ландшафтов Катуни становятся труднодоступными, менее привлекательными и как следствие- уровень туристскорекреационного воздействия резко снижается.

Долинные луга исследованного участка по степени воздействия на этот ландшафт в целом совпадает с предыдущим. Кроме того, удаленные от Катуни биотопы местное население используют в качестве пастбищ и покосов.

В окрестностях города Горно-Алтайска обследованы также 2 типа ландшафтов в двух вариантах. Суходольные луговые биотопы, слабо затронутые деятельностью человека (небольшие участки покосов), располагаются на югозападном склоне горы Тугая. Высокий прессинг испытывает южный склон этой 
горы, на которой работает горнолыжный комплекс «Тугая». В зимний период здесь проводятся соревнования по горным лыжам и сноуборду, а в теплое время года - это место отдыха горожан. Круглый год происходит массовое восхождение горожан на гору.

Низкогорные березовые леса мало привлекательны для туристов, но используются местным населением для сбора грибов, ягод и папоротника. Измененный вариант ландшафта находятся вблизи рекреационного объектапруд «Еланда», с относительно развитой инфраструктурой (пляж, автобусная остановка, конные маршруты и др.) - место массового отдыха горожан.

Учеты проводили в 2016 г. до начала массового приезда туристов (конец мая - начало июня), в разгар туристического сезона (конец июля - начало августа) и ближе к его окончанию (конец августа - начало сентября).

Для выявления обилия пресмыкающихся использован маршрутный метод [12, с. 256-257; 16, с. 28]. Рептилий подсчитывали без ограничения ширины трансекта с последующим пересчетом на единицу площади по расстоянию от учетчика до животного в момент его обнаружения. Эта методика разработана для учета птиц [19, с. 146], но для рептилий эта методика усовершенствована, в связи с низкой вероятностью их встреч при поднятии травостоя и расчетом ширины трансекта для каждого вида отдельно по удвоенной средней дальности обнаружения. Обилие оценено как число особей на квадратный километр $[4$, c. $72-74]$.

Метод учёта амфибий для данного исследования был выбран простой, не требующий подготовительных работ. Изготовить ловчие канавки по общепринятой методике [3, с. 173-174; 9, с. 72] в местах скопления туристов не представлялось возможным. Кроме того, их работа начинается с середины июля, а сроки исследования были определены с конца мая, поэтому был выбран учет животных на маршрутах. Ширину трансекта определяли для каждого вида отдельно по удвоенной средней дальности обнаружения. Обилие оценено как число особей на квадратный километр [9, с. 86]. 
В каждом из выбранных ландшафтных урочищ с учетом амфибий и рептилий проходили около 2-3 км. Таким образом, учеты были максимально унифицированы для всех типов местообитаний и групп животных, в том числе для удобства сопоставления результатов.

Анализ устойчивости населения проведён по основным его характеристикам - число встреченных видов и суммарное обилие с использованием индексов разнообразия Шеннона и Симпсона. Статистическую значимость различий между индексами определяли с помощью ресэмплинга перестановочным (permutation) тестом [14, с.4-24] при 9999 рандомизациях. Все вычисления осуществляли с использованием программ Microsoft Excel и Paleontological Statistics [18, c. 2-9].

Результаты исследования и их обсуждение

Весенний период учетов характеризуется минимальным количеством видов во всех ландшафтных сочетаниях (табл. 1). Чаще всего встречается живородящая ящерица (Zootoca vivipara), которая является одной из наиболее типичных и многочисленных представителей герпетофауны нашего региона. Из восьми исследованных местообитаний она не встретилась только в суходольных лугах в окрестностях города (не характерные для неё места обитания) и в низкотравных луговых биотопах долины реки Катунь с высокой рекреационной нагрузкой. Напротив, в этих местообитаниях была встречена прыткая ящерица (Lacerta agilis), которая избегает густых травостоев, предпочитая участки с проективным покрытием от 20 до 50\% [13, с. 139]. Кроме того, в брачный период окраска взрослых особей становится более яркой (особенно самцов), они становятся очень активные в течение всего дня, находясь в поисках партнеров, и как следствие - хорошо заметны. Единичные встречи остромордой лягушки (Rana arvalis) в лесных ландшафтах подверженных рекреационному воздействию можно объяснить расположению этих участков вблизи мест выплода и, вероятно, животные в этот период начинали миграции [17, с. 44-45]. 
Анализ внутриландшафтных отличий населения земноводных и пресмыкающихся данного периода исследований демонстрирует увеличение показателей обилия видов в биотопах, подверженных рекреационному воздействию.

Таблица 1

Показатели обилия земноводных и пресмыкающихся весеннего периода Катунского рекреационного участка в 2016 году, особей/км²

\begin{tabular}{|c|c|c|c|c|c|c|c|c|}
\hline \multirow[t]{2}{*}{ Вид } & \multicolumn{2}{|c|}{$\begin{array}{c}\text { Сосново- } \\
\text { берёзовые леса }\end{array}$} & \multicolumn{2}{|c|}{ Долинные луга } & \multicolumn{2}{|c|}{$\begin{array}{c}\text { Суходольные } \\
\text { луга }\end{array}$} & \multicolumn{2}{|c|}{ Берёзовые леса } \\
\hline & $\mathrm{B}$ & $\mathrm{H}$ & $\mathrm{B}$ & $\mathrm{H}$ & $\mathrm{B}$ & $\mathrm{H}$ & $\mathrm{B}$ & $\mathrm{H}$ \\
\hline $\begin{array}{l}\text { Остромордая } \\
\text { лягушка }\end{array}$ & 357 & 0 & 0 & 0 & 0 & 0 & 378 & 0 \\
\hline $\begin{array}{l}\text { Живородящая } \\
\text { ящерица }\end{array}$ & 248 & 285 & 0 & 286 & 0 & 0 & 1623 & 289 \\
\hline $\begin{array}{l}\text { Прыткая } \\
\text { ящерица }\end{array}$ & 0 & 0 & 2083 & 0 & 288 & 1616 & 0 & 0 \\
\hline
\end{tabular}

Условные обозначения: В- высокий, $H$ - низкий уровень туристскорекреационного воздействия.

Вторая половина лета характеризуется увеличением видового разнообразия и числа встреченных особей всех представителей герпетофауны изучаемого района (табл. 2). Вместе с тем вектор предпочтений видов меняется в противоположенную сторону. Так на контрольных участках сосново-берёзовых лесов и в слабонарушенных рекреацией лугах долины Катуни зарегистрирована озёрная лягушка (Pelophylax ridibundus). Это, возможно, связано с тем, что весной эти амфибии добывают больше водных организмов, чем наземных и не уходят далеко от берега. С увеличением доли активных наземных объектов питания в рационе этой лягушки увеличивается количество их встреч на суше [15, с. 48]. Кроме того, высокая влажность, обильные туманы, затяжные дожди этого периода учетов привели к образованию большого числа непересыхающих больших луж, болотин, где и были найдены озёрные лягушки.

Увеличивается в этот период и число встреч живородящей ящерицы, особенно в берёзовых лесах близ рекреационного объекта «Еланда». Однако невы- 
сокое обилие её на участках с низкой антропогенной нагрузкой вполне объяснимо [2, с. 99]. Этот лес загущен древесно-кустарниковым подростом и валежником, поэтому животные фиксировались только на открытых хорошо прогреваемых участках. Напротив, лес с высокой нагрузкой достаточно увлажнён (много открытых полян с небольшими ручьями), мозаичен (закрытые участки чередуются с открытыми, хорошо прогреваемыми луговинами), много тропинок, а травостой значительно примят отдыхающими.

За весь период учетов в Катунском рекреационном районе в суходольных контрольных лугах окрестности города во второй половине лета зарегистрирован единственный экземпляр обыкновенной гадюки (Vipera berus).

Таблица 2

Показатели обилия земноводных и пресмыкающихся Катунского рекреационного участка второй половины лета 2016 года, особей/км²

\begin{tabular}{|l|c|c|c|c|c|c|c|c|}
\hline \multirow{2}{*}{ Вид } & \multicolumn{2}{|c|}{$\begin{array}{c}\text { Сосново- } \\
\text { берёзовые леса }\end{array}$} & \multicolumn{2}{c|}{ Долинные луга } & \multicolumn{2}{c|}{$\begin{array}{c}\text { Суходольные } \\
\text { луга }\end{array}$} & \multicolumn{2}{c|}{ Берёзовые леса } \\
\cline { 2 - 10 } & $\mathrm{B}$ & $\mathrm{H}$ & $\mathrm{B}$ & $\mathrm{H}$ & $\mathrm{B}$ & $\mathrm{H}$ & $\mathrm{B}$ & $\mathrm{H}$ \\
\hline $\begin{array}{l}\text { Остромордая } \\
\text { лягушка }\end{array}$ & 0 & 0 & 0 & 476 & 0 & 0 & 0 & 571 \\
\hline $\begin{array}{l}\text { Озёрная } \\
\text { лягушка }\end{array}$ & 0 & 2174 & 1071 & 0 & 0 & 0 & 0 & 0 \\
\hline $\begin{array}{l}\text { Живородящая } \\
\text { ящерица }\end{array}$ & 476 & 1010 & 476 & 1111 & 0 & 0 & 4889 & 3667 \\
\hline $\begin{array}{l}\text { Прыткая яще- } \\
\text { рица }\end{array}$ & 0 & 2020 & 556 & 0 & 1000 & 550 & 0 & 0 \\
\hline $\begin{array}{l}\text { Гадюка обыкно- } \\
\text { венная }\end{array}$ & 0 & 0 & 0 & 0 & 0 & 416 & 0 & 0 \\
\hline
\end{tabular}

Позднелетние учеты показали спад видового разнообразия и суммарного обилия видов (табл. 3). При этом во многих местообитаниях животные не регистрировались вовсе. В частности, суходольные и долинные луга, за исключением рекреационных участков долины Катуни показали нулевой результат в учетах. Амфибии и рептилии не зафиксированы и в сосново-берёзовых лесах с высоким уровнем антропогенной нагрузки. Напротив, в берёзовых лесах вблизи 
пруда «Еланда» встречено три вида из четырёх, выявленных в позднелетний сезон исследований.

Сопоставление внутриландшафтных отличий выявило совпадение с весенним трендом предпочтения значительной частью видов амфибий и рептилий участков с более высоким уровнем рекреации в берёзовых лесах и долинных лугах.

Таблица 3

Показатели обилия земноводных и пресмыкающихся Катунского рекреационного участка второй половины лета 2016 года, особей/км²

\begin{tabular}{|l|c|c|c|c|c|c|c|c|}
\hline \multirow{2}{*}{ Вид } & \multicolumn{2}{|c|}{$\begin{array}{c}\text { Сосново- } \\
\text { берёзовые леса }\end{array}$} & \multicolumn{2}{c|}{ Долинные луга } & \multicolumn{2}{c|}{$\begin{array}{c}\text { Суходольные } \\
\text { луга }\end{array}$} & \multicolumn{2}{c|}{ Берёзовые леса } \\
\cline { 2 - 9 } & $\mathrm{B}$ & $\mathrm{H}$ & $\mathrm{B}$ & $\mathrm{H}$ & $\mathrm{B}$ & $\mathrm{H}$ & $\mathrm{B}$ & $\mathrm{H}$ \\
\hline $\begin{array}{l}\text { Остромордая } \\
\text { лягушка }\end{array}$ & 0 & 0 & 0 & 0 & 0 & 0 & 476 & 0 \\
\hline $\begin{array}{l}\text { Озёрная } \\
\text { лягушка }\end{array}$ & 0 & 2647 & 0 & 0 & 0 & 0 & 0 & 0 \\
\hline $\begin{array}{l}\text { Живородящая } \\
\text { ящерица }\end{array}$ & 0 & 463 & 0 & 0 & 0 & 0 & 667 & 505 \\
\hline $\begin{array}{l}\text { Прыткая } \\
\text { ящерица }\end{array}$ & 0 & 0 & 667 & 0 & 0 & 0 & 671 & 0 \\
\hline
\end{tabular}

Для выявления характера изменений в населении земноводных и пресмыкающихся под влиянием туристско-рекреационной деятельности проведён анализ видового разнообразия. При этом более информативны оказались сведения по среднелетним показателям обилия животных, то есть за все периоды учетов приведённого исследования (табл. 4). Статистическая достоверность отличий по индексам Симпсона и Шеннона во всех сравниваемых сочетаниях в высшей степени достоверны $\mathrm{P}<0.001$, что означает адекватное отражение структурного разнообразия сообществ. Сообщества земноводных и пресмыкающихся некоторых биотопов, испытывающих антропогенное воздействие, имеют более высокие показатели индексов, в сравнении с контрольными участками. Сосновоберезовые леса близ Катуни по сравнению с березовыми в окрестностях города более аридны. Менее плотные кроны и разреженность деревьев позволяет про- 
никать под полог леса бо́льшому количеству тепла, влаги и света. Близость Катуни определяет наличие песка в грунте и способствует быстрому проникновению осадков в почву, а её остатки быстро испаряются. Именно в сосновоберезовых лесах и суходольных лугах высокие интегральные показатели характерны для неизменённых вариантов.

Описанная выше ситуация прослеживается в разные сезоны исследований в биотопах с высоким обилием живородящей и прыткой ящериц, типичных и многочисленных видов нашей герпетофауны.

Показатели видового разнообразия населения земноводных и пресмыкающихся Катунского рекреационного участка

\begin{tabular}{|l|c|c|c|c|c|c|c|c|}
\hline \multirow{2}{*}{ Показатель } & \multicolumn{2}{|c|}{$\begin{array}{c}\text { Сосново- } \\
\text { березовые леса }\end{array}$} & \multicolumn{2}{c|}{ Долинные луга } & \multicolumn{2}{c|}{$\begin{array}{c}\text { Суходольные } \\
\text { луга }\end{array}$} & \multicolumn{2}{c|}{ Березовые леса } \\
\cline { 2 - 10 } & $\mathrm{B}$ & $\mathrm{H}$ & $\mathrm{B}$ & $\mathrm{H}$ & $\mathrm{B}$ & $\mathrm{H}$ & $\mathrm{B}$ & $\mathrm{H}$ \\
\hline $\begin{array}{l}\text { Видовое } \\
\text { богатство }\end{array}$ & 2 & 3 & 3 & 2 & 1 & 2 & 3 & 2 \\
\hline $\begin{array}{l}\text { Суммарное } \\
\text { обилие }\end{array}$ & 360 & 2860 & 1618 & 625 & 429 & 861 & 2902 & 1776 \\
\hline $\begin{array}{l}\text { Индекс } \\
\text { Симпсона }\end{array}$ & 0,44 & 0,59 & 0,48 & 0,38 & 0 & 0,27 & 0,30 & 0,20 \\
\hline $\begin{array}{l}\text { Индекс } \\
\text { Шеннона }\end{array}$ & 0,63 & 0,99 & 0,82 & 0,57 & 0 & 0,44 & 0,58 & 0,35 \\
\hline
\end{tabular}

\section{Заключение}

Таким образом, можно отметить неоднозначную реакцию сообщества земноводных и пресмыкающихся Катунского рекреационного участка на антропогенную нагрузку, как по сезонам, так и по биотопам. Характер изменения сообществ зависит от интенсивности рекреационного природопользования. Подобное влияние может оказывать лимитирующее действие, но при этом способствовать увеличению распространения отдельных видов. Анализ показателей индексов Шеннона и Симпсона выявил тенденцию зависимости степени гумидности на изменение в структуре населения земноводных и пресмыкающихся. В условиях умеренной и низкой увлажнённости местообитаний рекреация негативно воздействует на сообщества амфибий и рептилий, а в гумидных био- 
топах способствует увеличению широты распространения и численности некоторых видов герпетофауны.

В целом, сообщества земноводных и пресмыкающихся реагирует на степень туристско-рекреационного воздействия, причем как в начале сезона и его продолжении, так и по завершению исследований.

Исследование выполнено при поддержке грантом РФФИ №16-45-040158 p_a.

\section{Сиисок литературы}

1. Доклад о состоянии и об охране окружающей среды Республики Алтай в 2014 году [Текст] / Под ред. Ю.В. Робертуса. - Горно-Алтайск, 2015. - 122 с.

2. Дуйсебаева Т.Н. Распространение и экология живородящей ящерицы Zootoca vivipara (Jacquin, 1787) в Маркакольской котловине и прилежащих районах Восточного Казахстана [Текст] / Т.Н. Дуйсебаева, В.Ф. Орлова // Современная герпетология. - 2009. - Т. 9. - № 3/4. - С. 91-102.

3. Калецкая М.Л. Фауна земноводных и пресмыкающихся Дарвинского заповедника и ее изменения под влиянием Рыбинского водохранилища [Текст] / М.Л. Калецкая // Рыбинское водохранилище. - М.: Изд-во МОИП, 1953. -Ч. 1. 1953. - C. 171-186.

4. Ливанов С.Г. Мониторинг Разнообразия наземных позвоночных государственного биосферного заповедника «Катунский» (концепция, методы и варианты реализации) [Текст] / С.Г. Ливанов, Ю.С. Равкин // Труды государственного природного биосферного заповедника Катунский. - Барнаул:Издво АГУ, 2001. - №1. - С. 55-110.

5. Малков П.Ю. Влияние рекреационного природопользования на биотопические группировки дневных бабочек (на примере Катунского рекреационного района Республики Алтай) [Текст] / П.Ю. Малков // Международный журнал прикладных и фундаментальных исследований. Биологические науки.2016. - №9. - C. 252-256.

6. Министерство экономического развития и туризма Республики Алтай. Официальный сайт. - 2016 [Электронный ресурс]. - Режим чтения: 
http://www.mineco04.ru/strategicheskoe-plnirovanie/prognoz-razvitiya/analitika.php (дата обращения: 29.10.2016).

7. Павлова К.С. Характер изменения свойств и состава почв рекреационных территорий (на примере Катунского района Республики Алтай) [Текст] / К.С. Павлова, Ю.В. Робертус, А.В. Кивацкая // Мир науки, культуры и образования. - 2013. - №1 . - С. 338-342.

8. Пястолова О.А. Использование бесхвостых амфибий в биоиндикации природной среды [Текст] / О.А. Пястолова, Е.А. Трубецкая // Биоиндикация наземных экосистем. - Свердловск: УрО АН СССР, 1990. - С. 18-30.

9. Равкин Ю.С. Факторная зоогеография: Принципы, методы и теоретические представления [Текст] / Ю.С. Равкин, С.Г. Ливанов. - Новосибирск: Наука, 2008. - 205 с.

10. Робертус Ю.В. Основные проблемы рекреационного природопользования в Республике Алтай и пути их решения [Текст] / Ю.В. Робертус, К.С. Павлова // Материалы международной конференции Биоразнообразие, проблемы экологии Горного Алтая и сопредельных регионов: Настоящее, прошлое, будущее. - Горно-Алтайск: РИО ГАГУ, 2013. - С. 381-385.

11. Савченко И.М. Проблемы рекреационного природопользования Республики Алтай [Текст] / И.М. Савченко, П.Ю. Андросова // Материалы Международной конференции Биоразнообразие, проблемы экологии Горного Алтая и сопредельных регионов: Настоящее, прошлое, будущее.- Горно-Алтайск: РИО ГАГУ, 2016. - С. 416-417.

12. Теплов В.П. Учет животных на постоянных маршрутах [Текст] / В.П. Теплов // Методы учета численности и географического распределения наземных позвоночных. - М.: Изд-во АН СССР, 1952. - С. 255-259.

13. Чирикова М.А. Материалы к распространению, биотопическому и вертикальному размещению прыткой ящерицы (Lacerta agilis Linnaeus, 1758) на юго-востоке ареала [Текст] / М. А. Чирикова, Н. Н. Березовиков // Современная герпетология. - 2015. - Т. 15. - С. 130-145. 
14. Шитиков В.К. Использование рандомизации и бутстрепа при обработке результатов экологических наблюдений [Текст] / В.К. Шитиков // Принципы экологии. - 2012. - Т. 1. - №1. - С. 4-24.

15. Шляхтин Г.В. Сезонная изменчивость пищевого рациона озёрной лягушки - Pelophylax ridibundus (Pallas, 1771) на севере Нижнего Поволжья [Текст] / Г.В. Шляхтин, В.Г. Табачишин // Современная герпетология. - 2010. T. 10. - C. 47-53.

16. Щербак Н.Н. Земноводные и пресмыкающиеся Крыма [Текст] / Н.Н. Щербак. - Киев: Наук. думка, 1966. - 240 с.

17. The Amphibians of Belarus / S.M. Drobenkov, R.V. Novitsky, L.V. Kosova [et al] // Sofia. - M., 2005. - 177 p.

18. Hammer Ø. PAST: Paleontological Statistics software package for education and data analysis / Ø. Hammer, D.A.T. Harper, P.D. Ryan // Palaeontologia Electronica. - 2001. - №4.- 9 p. [Электронный pecypc]. - Режим доступа: http://folk.uio.no/ohammer/past/Past3.zip

19. Hayne Don.W. An examination of the strip census method for estimating animal populations / Don.W. Hayne // The journal of wildlife Management. - 1949. V. 13. - №2. - P. 145-147.

20. The Natural climatic conditions for the economic activity in mountain areas (in the case of the Altai Republic) / M.G. Sukhova, O.V. Zhuravleva, N.A. Kocheeva [et al] // Life Science Journal. - 2014. - №11. - P. 664-668.

Вознийчук Ольга Петровна - канд. биол. наук, доцент кафедры ботаники, зоологии, экологии и генетики ФГБОУ ВО «Горно-Алтайский государственный университет», Россия, Горно-Алтайск.

Vozniychuk Olga Petrovna - candidate of biological sciences, assistant professor of the Department of Botany, Zoology, Ecology and Genetics FSFEI of HE "Gorno-Altaisk State University", Russia, Gorno-Altaisk. 